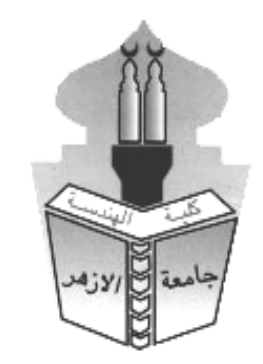

\title{
THE IMPACT OF CLIMATE CHANGE ON COASTAL CITIES IN THE EASTERN NILE DELTA OF EGYPT
}

\section{Hany G. I. Ahmed}

Civil Engineering Department, Faculty of Engineering, Al Azhar University, Nasr City ,Egypt

Received :12 Nov. $2021 \quad$ Accepted:13 Dec. 2021

\begin{abstract}
Rising sea levels, along with the more powerful and frequent extreme events of waves, will result in not just coastal inundation, but also led to increase in beach erosion. Offshore wave propagation in coastal regions is impacted by changes in water depth related to the bathymetry of the seabed and tides. The coastal along the Nile Delta is extremely sensitive to a faster rise in sea level (SLR) due to its low-lying topography, while at the same time the area has a high socio-economical and touristic value. As a result, quantifying SLR effects on morph dynamics in this area is important to examine the relation between SLR, wave height, wave power, and currents. The influence of SLRs on waves and currents is studied using coupled hydrodynamic and spectral wave, numerical models. The effectiveness of the predicted result from the numerical model is evaluated by comparison with some available field measurements. It is demonstrated that waves and currents in this region are sensitive to the trend in SLR and that a potential climate change scenario will result in a large rise in exceptional wave heights. The results of the numerical model can be accepted where it is able to predict the characteristics of waves and currents and detect the harmful impact of SLR on the coastal area.
\end{abstract}

Keywords: Coastal Zone; Climate change; SLR; Wave height; Currents.

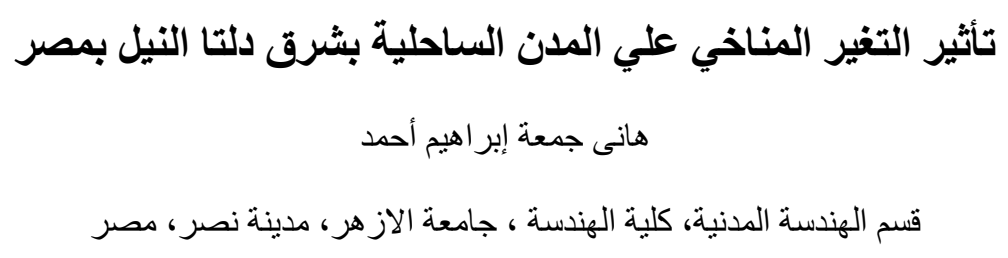




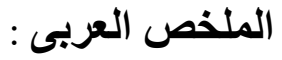

إرتفاع مستوى سطح البحر والعو اصف الأكثر قوة وتكر ارًا لا نسبب فقط غمر للسو احل ولكن تسبب مشاكل أخري مثل زيادة

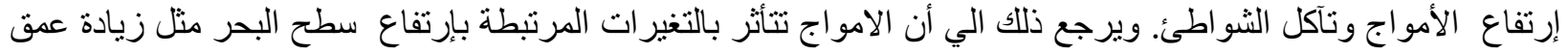

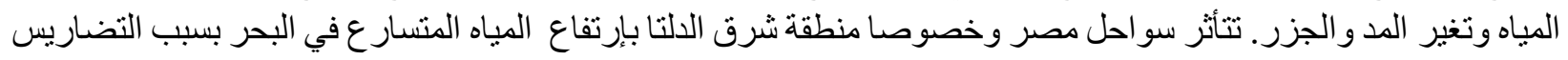

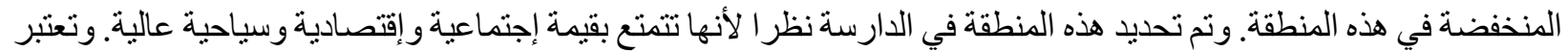

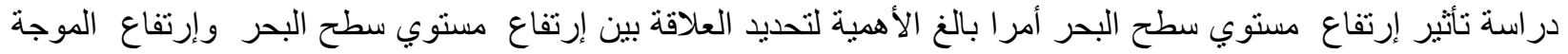

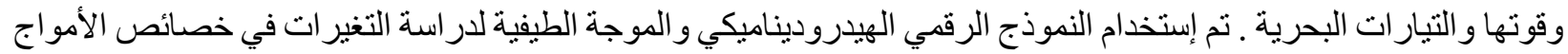

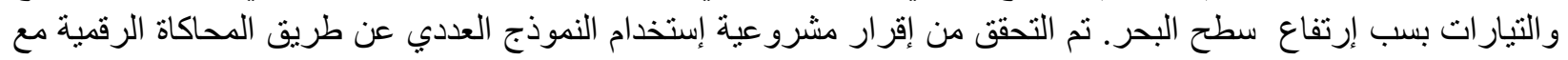

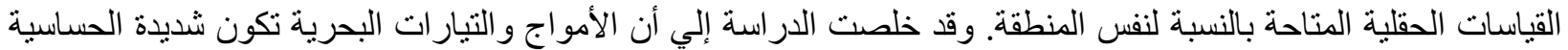

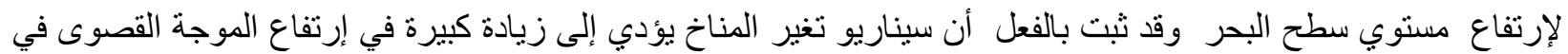

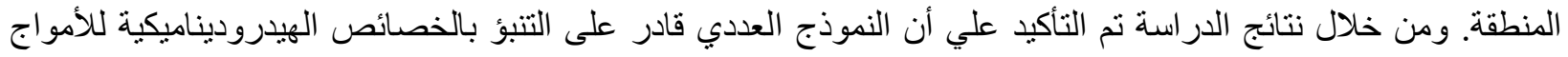
و التيار ات البحرية بما في ذلك التأثثر السلبي علي المنطقة الساحلية الناتج عن إرتفاع مستوي سطح التح البحر.

\section{Introduction}

In the last decades, climate change effects on Sea level have been observed on a global scale. The major contributing factors to sea level rise (SLR) are oceans and glaciers. Nowadays, researchers' attention is focused on studying the effect of climate change in SLR, and the resulting change in the characteristics of waves and currents. Many local and international studies have focused on studying the dramatic impact of SLR on the coasts of Egypt. A combination of different numerical simulation models is carried out using SWAN and FLOW-3d models [1]. The susceptibility of the Alexandria coastal area, to the local sea-level rise, is assessed [2]. This study was implemented by evaluating land elevation datasets with a sea-level rise scenario of $1 \mathrm{~m}$. The emissions of the first decades of the 21 century alone will result in significant long-term SLR [3]. Future projections of the sea level show that it is essentially predictable to continue to rise in the current century and beyond [4]. The response to the rise of the sea level depends heavily on local human and natural conditions. Over more than 20 years, sea levels have risen around three times faster than the global mean in some areas, while the world average rates had been slower than the global mean in other areas [5]. The rate of rise in the global average sea level has improved over the years since 1900 [6], [7]. However, due to the combined effects of ocean currents, melting land ice mass losses, land waters store changes, ocean thermal expansion, and changes in water density, the SLR is much less consistent on temporal and local scales [8], [9]. Modern measurements have shown significant regional sea level variations from the global average, showing that regional patterns vary across a wide spectrum of space and time. The underlying changes in regional temperature and salinity are due to ocean circulation changes generated by forcing the surface wind [10]. Therefore, the impacts of SLR for local areas, and in particular hydrodynamic studies, are necessary to conduct local research. A major effect of climate change is an increase in sea level. The global increase in sea level is caused by the combination of thermal expansion of the oceans and an increase in continental glacial melting [11]. SLR will have far-reaching consequences for many coastal 
populations and the systems on which they depend. People residing in the coastal areas of the countries are at risk and are becoming vulnerable, leading to their homes being lost and people being displaced.

This article details a numerical model that is developed by Danish Hydraulic Institute (DHI) to evaluate the impact of SLR on the hydrodynamic patterns in the study area. The impacts of SLR, like floods, erosion, and the intrusion of saltwater, have adversely affected all developed activities, justifying the need and relevance of forecasting the hydro-dynamic trends in the study area caused by climate change. In order to stimulate effective and integrated coastal management, it is vital to anticipate the impact of SLR, identify coastal vulnerabilities, and to provide useful information to authorities responsible for the safety of population, property and economic activity.

\section{Data and Methods}

\subsection{Study area}

The study area in the coastal zone runs in the direction of the west to the east and extends about $25 \mathrm{~km}$. The wind data reveals that the north-west winds have a strong influence on the wave and the coastal morphology in the Nile Delta. On the other hand, the recorded wave data of the wave gauge located approximately at depth of $18 \mathrm{~m}$ near Damietta Harbor (figure 1) reveals that the study area is exposed to dominant north-west waves of $1.65 \mathrm{~m}$ height, while the maximum wave height was $5.24 \mathrm{~m}$ in the available recorded data. It is known that the wave is the most influential factor in the hydrodynamic process in the domain of the Mediterranean Sea, this is because the recorded tidal measurements were observed ranging from 0.2 to $0.4 \mathrm{~m}$ (figure 3 ).

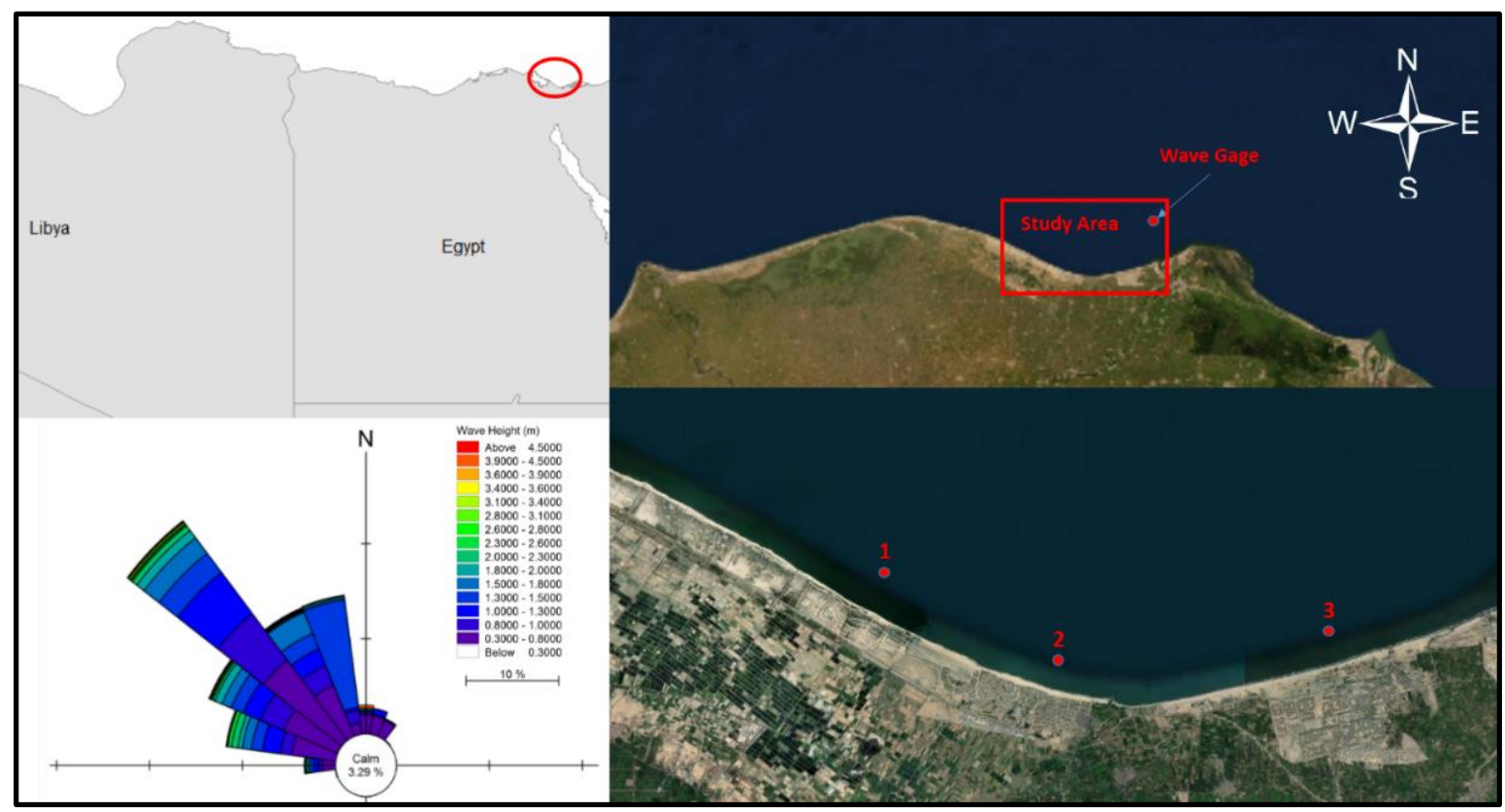

Figure 1. The study area and annual wave rose. 


\subsection{Numerical modeling}

The numerical model used in this study is MIKE 21, which has been developed by the Danish Hydraulic Institute, Denmark. A third-generation model based on unstructured meshes, MIKE 21 is a two-dimensional numerical model for simulating hydraulic and environmental processes in lakes, bays, coastal waters and seas, estuaries, and rivers. It consists of many modules that can be used to simulate 2D free surface flow. MIKE 21 is based on a parabolic approximation to the mildslope equation, which governs refraction, shoaling, diffraction, and reflection of linear water waves propagating on gently sloping bathymetry. The models simplify the Boussinesq hypothesis, hydrostatic pressure, and fluid incompressibility. The models use the numerical methodology of the finite volume method to solve the Navier Stokes equations [12]. This module's fundamental concept answers the continuity equation and vertically integral momentum conservation mass for 2HD (two horizontal dimensions), allowing it to describe the interplay of fluid variation with depth [13]. The following are the equations used in this module:

Continuity equation:

$\frac{\partial u}{\partial x}+\frac{\partial v}{\partial y}+\frac{\partial w}{\partial z}=s$

Momentum of mass in the X-direction:

$\frac{\partial u}{\partial t}+\frac{\partial u^{2}}{\partial x}+\frac{\partial v u}{\partial y}+\frac{\partial w u}{\partial z}+=f v-g \frac{\partial \eta}{\partial x}-\frac{1}{\rho_{o}} \frac{\partial P_{a}}{\partial x}-\frac{g}{\rho_{o}} \int_{z}^{\eta} \frac{\partial \rho}{\partial x} d z+F_{u}+\frac{\partial}{\partial z}\left(V_{t} \frac{\partial u}{\partial z}\right)+u_{s} S=0$

Momentum of mass in the Y-direction:

$\frac{\partial v}{\partial t}+\frac{\partial v^{2}}{\partial x}+\frac{\partial u v}{\partial y}+\frac{\partial w v}{\partial z}+=f u-g \frac{\partial \eta}{\partial y}-\frac{1}{\rho_{o}} \frac{\partial P_{a}}{\partial y}-\frac{g}{\rho_{o}} \int_{z}^{\eta} \frac{\partial \rho}{\partial y} d z+F_{v}+\frac{\partial}{\partial z}\left(V_{t} \frac{\partial v}{\partial z}\right)+v_{S} S=0$

Where:

$$
\begin{array}{ll}
x, y, z & : \text { Cartesian coordinates } \\
u, v, w & : \text { flow velocity components } \\
S & : \text { magnitude of discharge due to point sources } \\
g & : \text { acceleration due to gravity }\left(\mathrm{m} / \mathrm{s}^{2}\right) \\
f \mathrm{~V}, f \mathrm{u} & : \text { wind friction factor } \\
V, V_{x}, V_{y}(x, y, t) & : \text { wind speed and components in } \mathrm{x} \text { and } \mathrm{y} \text {-direction }(\mathrm{m} / \mathrm{s}) \\
P_{a}(x, y, t) & : \text { atmospheric pressure }\left(\mathrm{kg} / \mathrm{m} / \mathrm{s}^{2}\right) \\
\rho_{\mathrm{w}} & : \text { density of water }\left(\mathrm{kg} / \mathrm{m}^{3}\right) \\
t & : \text { time }(\mathrm{s})
\end{array}
$$

MIKE 21 is capable of solving models including complicated and multidisciplinary problems such as hydraulics, coastal engineering, and environmental science. The Hydrodynamic (HD) module 
is the basic module in the MIKE 21 flow model. It provides hydrodynamic basis modeling for computations performed. This module simulates water level variations and their flows to time in response to the force acting on it and the output results used as input in other modules [14]. This Spectral Wave Model (SW) simulates the propagation, growth, decay, and transformation of windgenerated waves and swells in offshore and coastal environments. Wave growth due to wind action, non-linear wave-wave interaction, dissipation due to obstacles, bottom friction, and depth-induced wave breaking, refraction and shoaling owing to depth changes, wave-current interaction are all included in the model. The effect of changing water depth over time, as well as flooding and drying, are considered in the model. MIKE 21 uses two types of numerical methods for the solution: Low Order and Higher Order. When compared to the second, the first has lower quality outcomes but less simulation time. Due to time constraints for the simulation, the Low Order scheme was used [13].

In the present study, the MIKE 21 coupled modules of Hydrodynamic (HD), and Spectral Wave (SW) developed by DHI are applied to model hydrodynamics and wave propagation along the study area under the impact of SLR. Particularly, the HD module is used to compute currents which are induced by waves, whilst the SW module is used for transformation of waves from offshore until near-shore wave field. The computational domain, about $580 \mathrm{~km}^{2}$, has open-sea boundary from the north, east, west and a shoreline-land boundary enclosing from the south (figure 2). The coupled model system is solved on a flexible 2D grid including 17634 triangular elements. Accordingly, a coarser mesh with the largest grid cell area of $150000 \mathrm{~m}^{2}$ is used for the offshore area and very fine mesh in near shore area along the study area beach (figure 2).

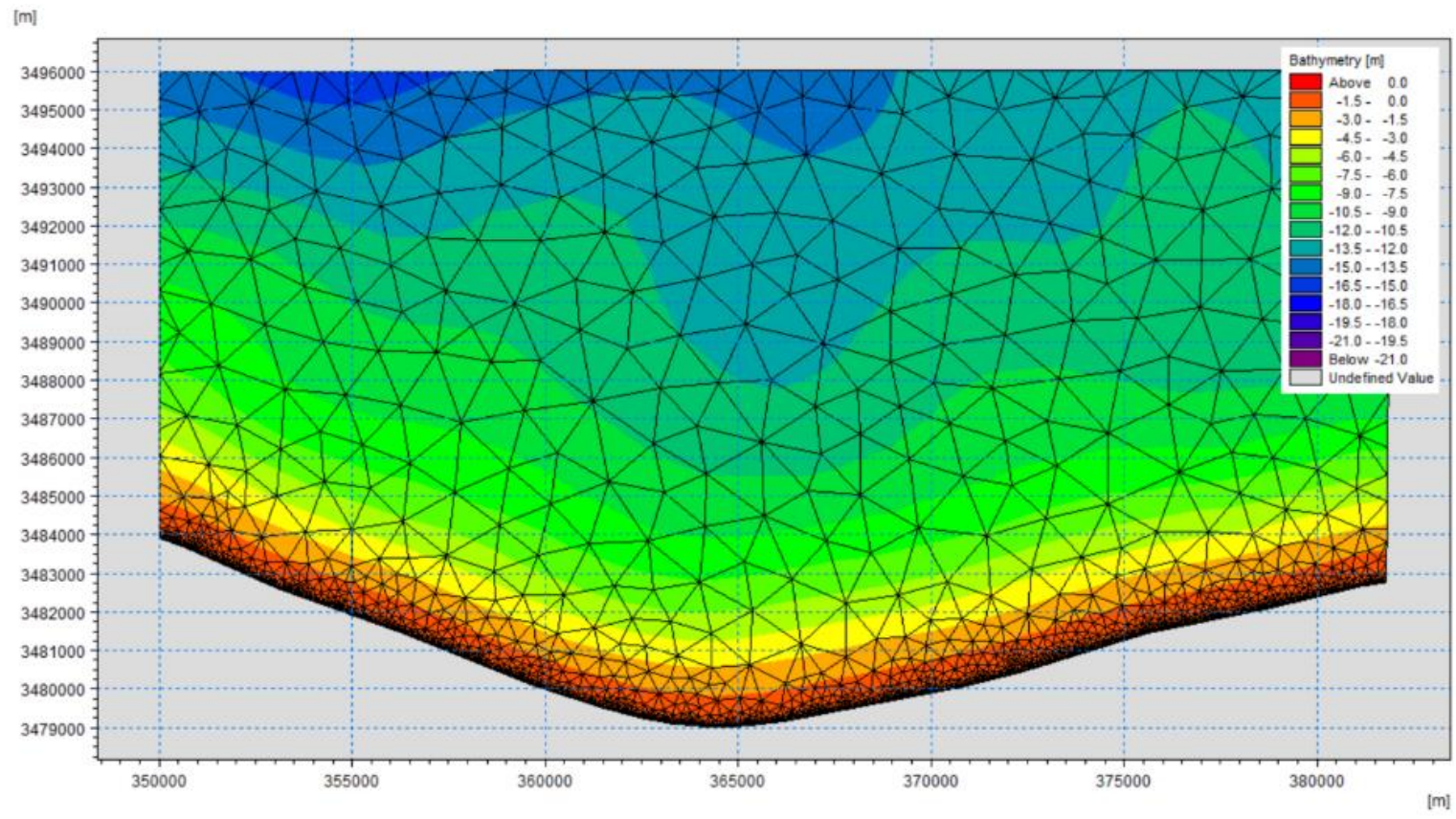

Figure 2. The computational mesh and bathymetry of the study area. 
When using MIKE21 Flow HD, the eddy viscosity and Manning's number are specified. Both of these variables are significant when modeling small areas and can have an impact on the outcome. Because the modeling field in this study is large, two values are chosen as default. Manning's number is 40 , and the eddy viscosity coefficient equals 1 . The study did not account for precipitation and evaporation, as well as tidal potential. They are not included due to the duration of the modeling time; their influence will be negligible and may thus be ignored. Following the execution of MIKE21, data on flow conditions, water height, and currents are obtained. MIKE21 SW will use this to obtain information on the wave conditions in the study area. The characteristics of waves, tides, radiation stresses, and currents will be evaluated. These characteristics are critical for studying coastal erosion and sediment movement. The findings from MIKE21 HD will be used in MIKE21 SW, and the output files from MIKE21 Flow HD will be used for current velocities, current direction, and surface elevation. With a gamma value of 0.8 , breaking waves are included. Bottom friction is determined by the size of the sediment particles at the site, and here it is determined by the coarsest layer because the sediment is frozen for the majority of the time and will behave as though particles are coarser. MIKE 21, unlike other models, uses a dynamic time step chosen by the model to validate the CFL number. Only the minimum and maximum time steps, as well as the critical CFL number, must be specified by the user. A minimum and maximum time step of 60 and 600 seconds was used in all simulations. The essential CFL value selected was 0.8 . The low-order numerical approach was used for all simulations.

\subsection{Study scenarios}

The wave parameters are computed using observed wave data. This information is fed into the boundary condition, and the program is built around it. Two wave conditions are modelled in order to clarify and quantify the effect of SLR in the examined area. The observed wave data in 20052006 was used to generate the input data for the numerical simulations in SLR circumstances. For dominant wave conditions, the wave height is $1.65 \mathrm{~m}$, the period is 9.1 seconds, and direction is 315. On the other hand, in the maximum wave condition, the wave height is $5.24 \mathrm{~m}$, the period is 10.7 seconds, and the direction is 315 . Regarding the SLR parameters, three SLR scenarios are modeled: $0.0 \mathrm{~m}, 0.50 \mathrm{~m}, 1.00 \mathrm{~m}$.

\section{Results and Discussion}

The results of the model simulation in the coastal area are provided in this section. The first element of discussion is model validation. The results of the simulation of wave height are presented in the second part, the results of wave power are discussed in the third part, and the results of current speed are represented in the fourth part.

\subsection{Model Validation}

Validation of the numerical results with measured field data is needed to ensure that the results are accurate. Due to the unavailability of field records for the study area, the numerical model of the study area is validated only by comparison tidal of the numerical model with the recorded data of 
a period 27-October to 14-December 1998. The model results were compared to tide measurements taken at the Alexandria Harbor station. Figure 3 depicted a comparison of measured tidal data and model results, revealing that the average error value is 5\%. As a result, the result of the tidal parameter modelling approaches the actual conditions in the Alexandria Harbor station data.

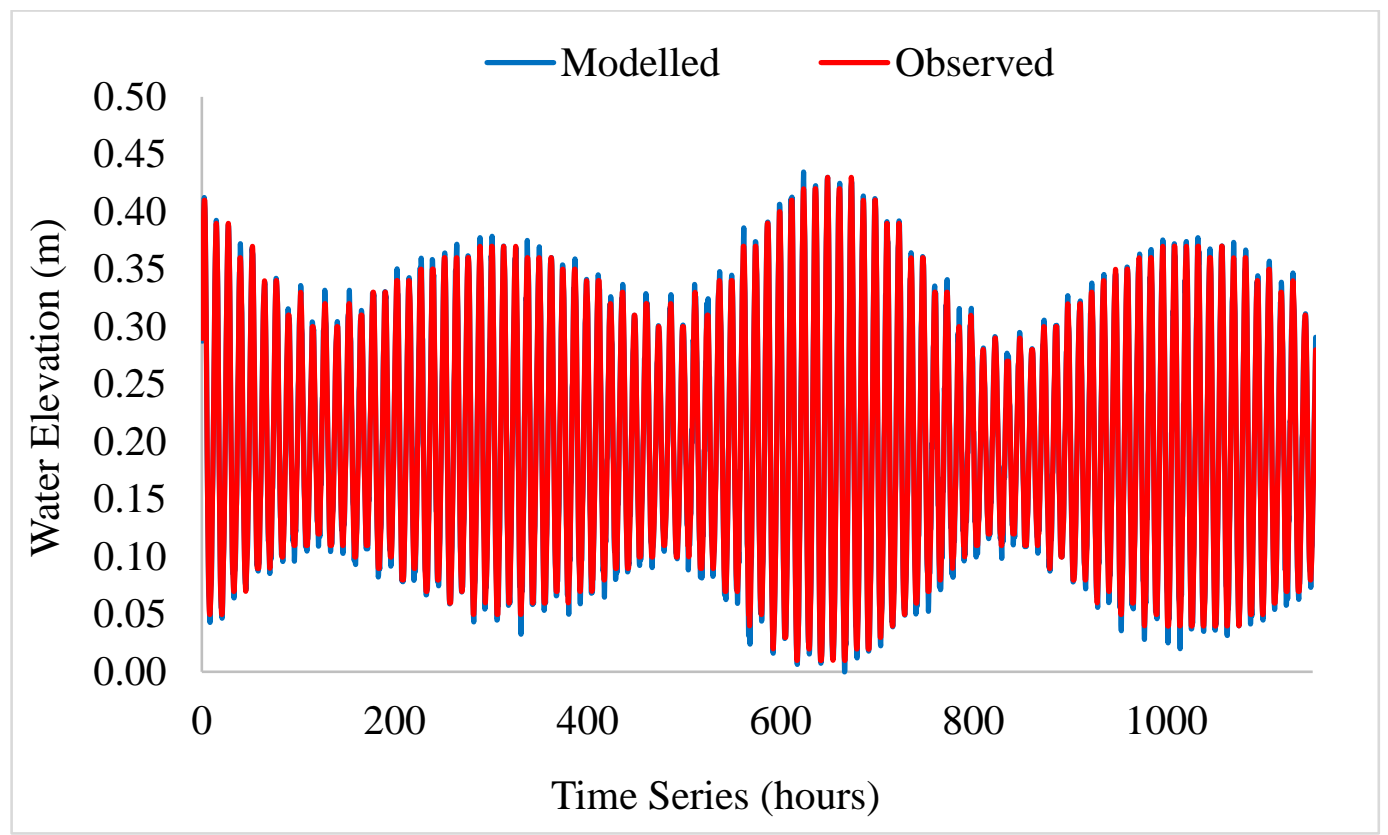

Figure 3. Comparison between the model water level and the recorded water level, from 27 October to 14 December 1998.

\subsection{Effects of SLR on Waves}

The coast of the study area is mainly influenced by the main wave direction northwest. Particularly for the first scenario, the mean significant wave heights, Hs, found at the water depth of about $3.75 \mathrm{~m}$ near the three locations under the impacts of the dominant wave are about $1.23 \mathrm{~m}, 1.22 \mathrm{~m}$, and $1.35 \mathrm{~m}$, respectively (figure 4). However, all wave heights eventually diminish when they travel in shallow water areas and are absorbed by the friction of the seabed. Deeper water areas allow larger waves to approach and break closer to the coastline as SLRs, leading to increased wave heights in near shore zones. Particularly in the second location beach, the mean significant wave height with the scenario SLR $(0.50 \mathrm{~m}$ and $1.00 \mathrm{~m})$ from $1.24 \mathrm{~m}$ to $1.25 \mathrm{~m}$ in dominant wave (figures 4); while its value ranges from $2.48 \mathrm{~m}$ to $2.63 \mathrm{~m}$ in the maximum wave (figures 5). Indeed, for dominant wave conditions, the mean wave heights near the study area beach are increased by $1.98 \%-1.29 \%-2.56 \%$ for the second scenario. The third scenario induces the largest increase of wave height up to $3.88 \%$ at the third location beach, compared with the other cities (figure 6). When SLR occurs along with the maximum wave as a result, the near shore significant wave height is intensified by $12.62 \%-12.88 \%-13.91 \%$ at the water depth of $3.75 \mathrm{~m}$ for the third scenario (figure 7). An increasing trend in wave height is found in all the SLR scenarios, but the maximal increase 
occurs in the third location beach, and it reduces when the SLR decreases. The wave height is boosted by $6.72 \%-13.91 \%$ in the third location beach, compared with the case without SLR (figure

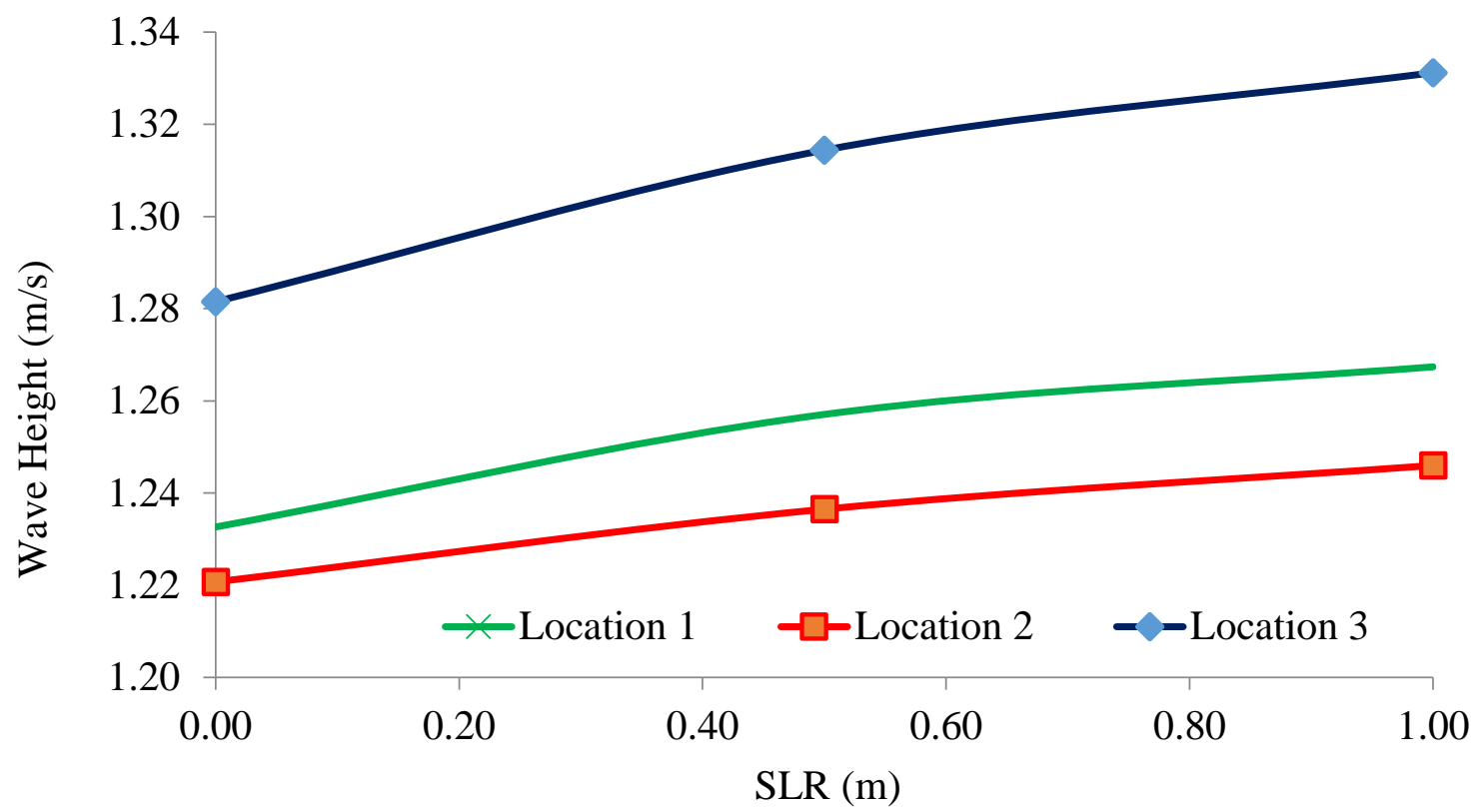

7).

Figure 4. For the dominant wave, wave height under the influence of SLR.

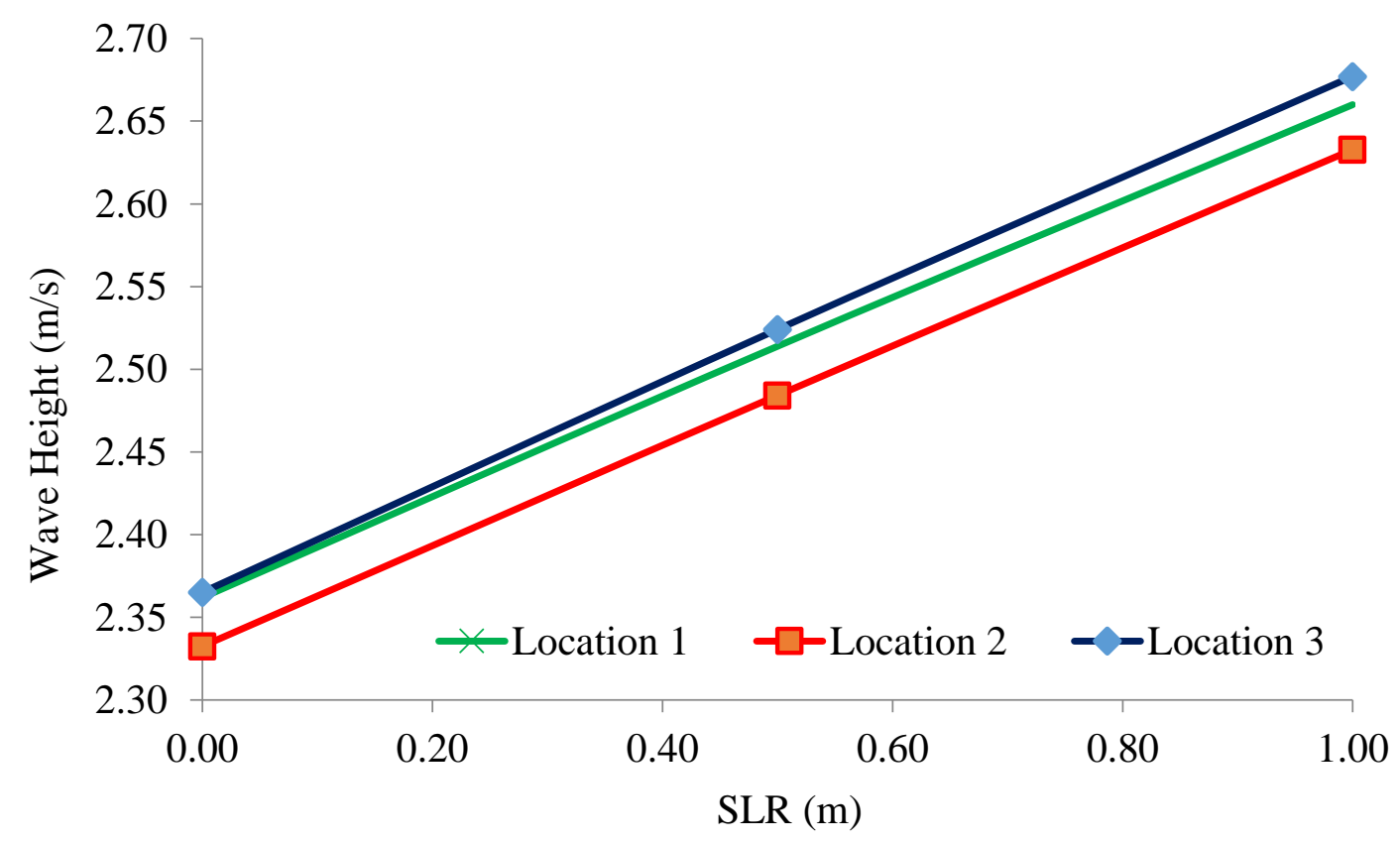

Figure 5. For the maximum wave, wave height under the influence of SLR. 


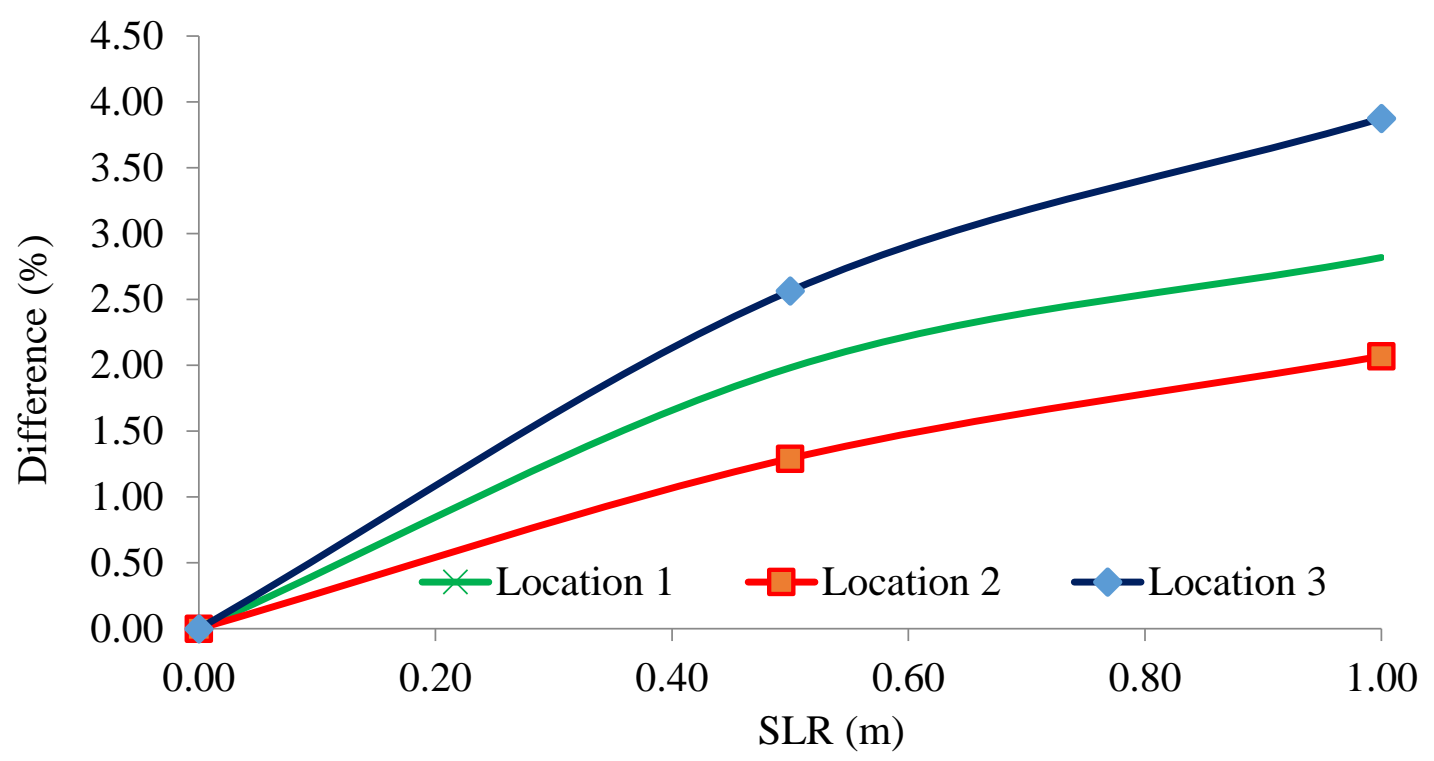

Figure 6. For the dominant wave, difference in wave height under the influence of SLR.

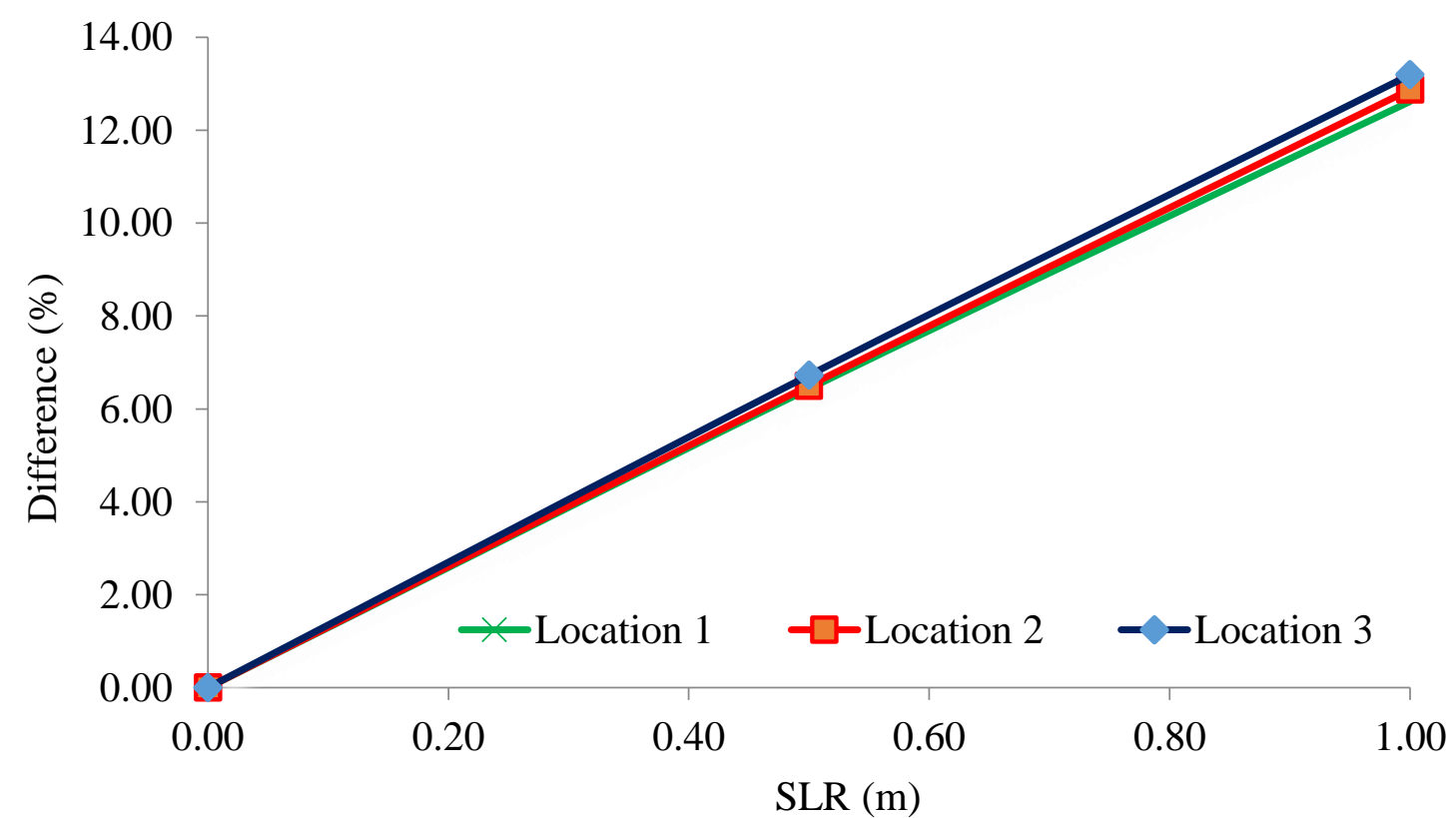

Figure 7. For the maximum wave, difference in wave height under the influence of SLR.

SLR reduces bottom friction and increases water depth relative to wave height, leading to larger and more powerful waves that might reach the beaches (figures $8 \& 9$ ). As sea level increases, the propagation of dominant waves over the shallow waters results in higher wave power, boosted by 6.71\%:5.46\%:5.05\% at a water depth of 3.75m in front of the beaches when SLR is about $0.50 \mathrm{~cm}$ (figure 10). But the maximum increase occurs when SLR is $1.00 \mathrm{~m}$ as the wave power increases by 11.08\%:9.77\%:9.01\% (figure 10). An increasing trend in wave power is found in all the SLR 
scenarios, but the maximal increase occurs in the third location beach as it reduces when the SLR decreases. The wave power is boosted by 15.6\%:35.53\% in the study area, compared with the case without SLR (figure 11). When SLR occurs along with the maximum wave, an increase in wave heights would generate a corresponding rise in wave power.

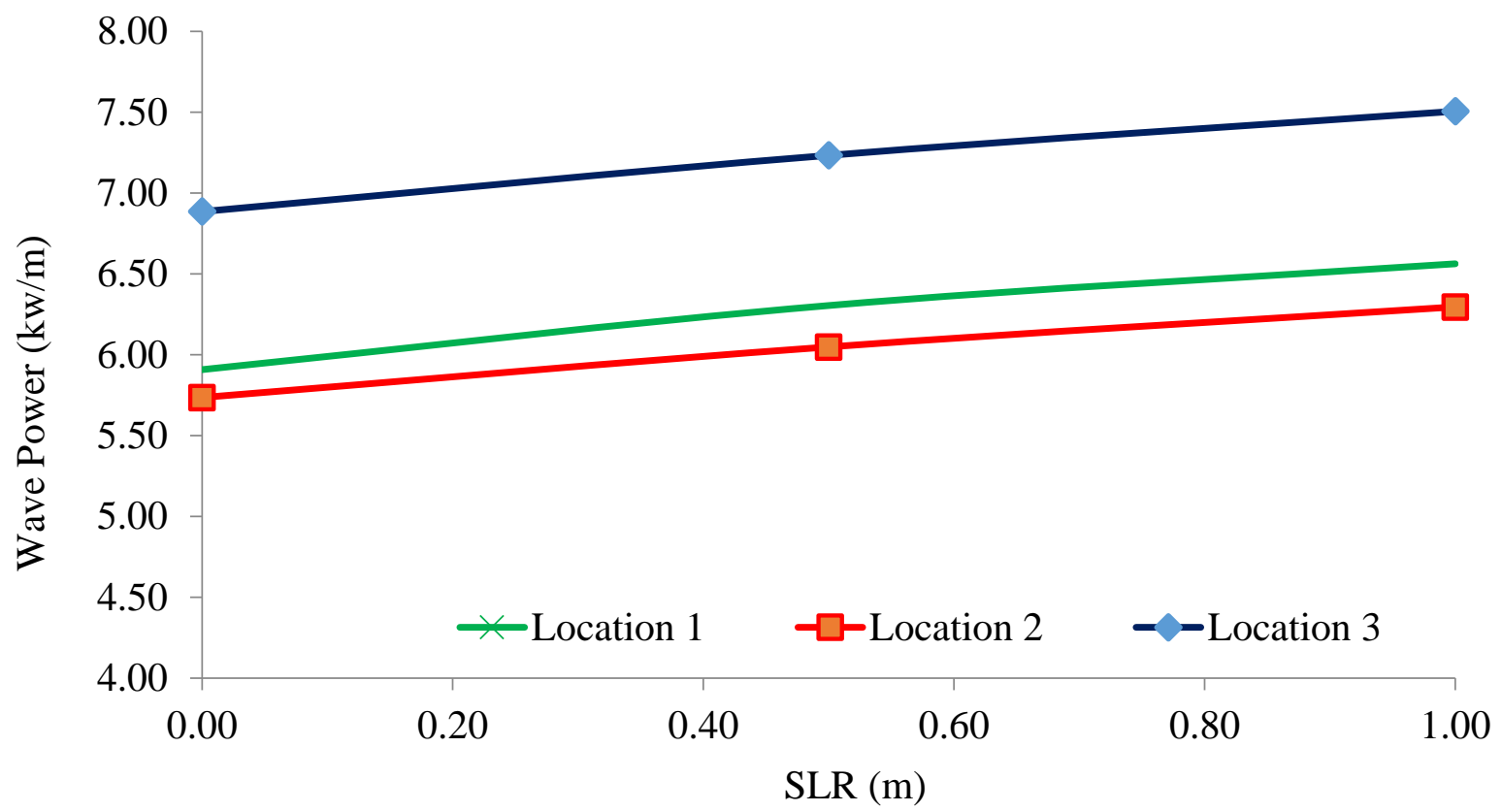

Figure 8. For the dominant wave, wave power under the influence of SLR.

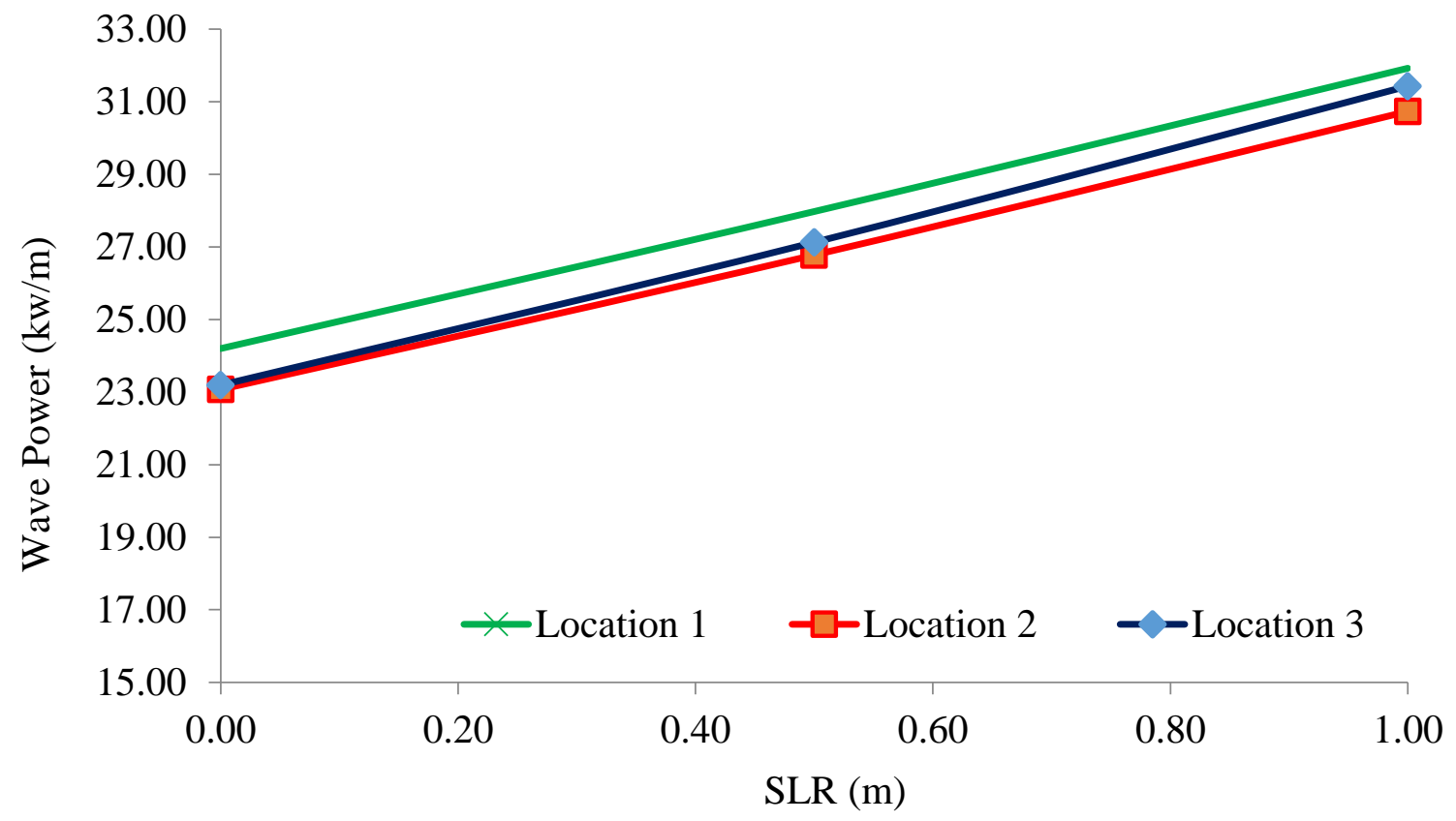

Figure 9. For the maximum wave, wave power under the influence of SLR. 


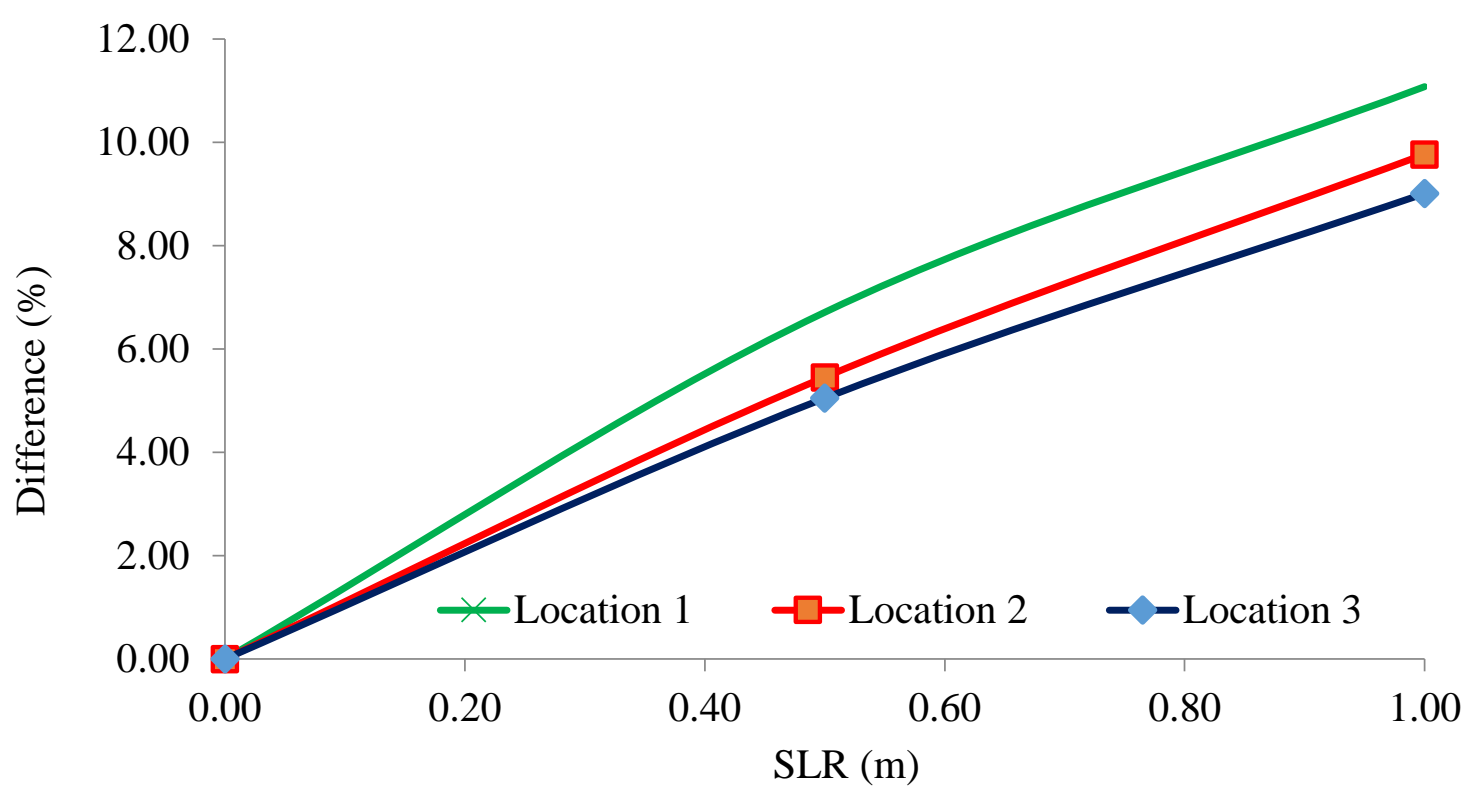

Figure 10. For the dominant wave, difference in wave power under the influence of SLR.

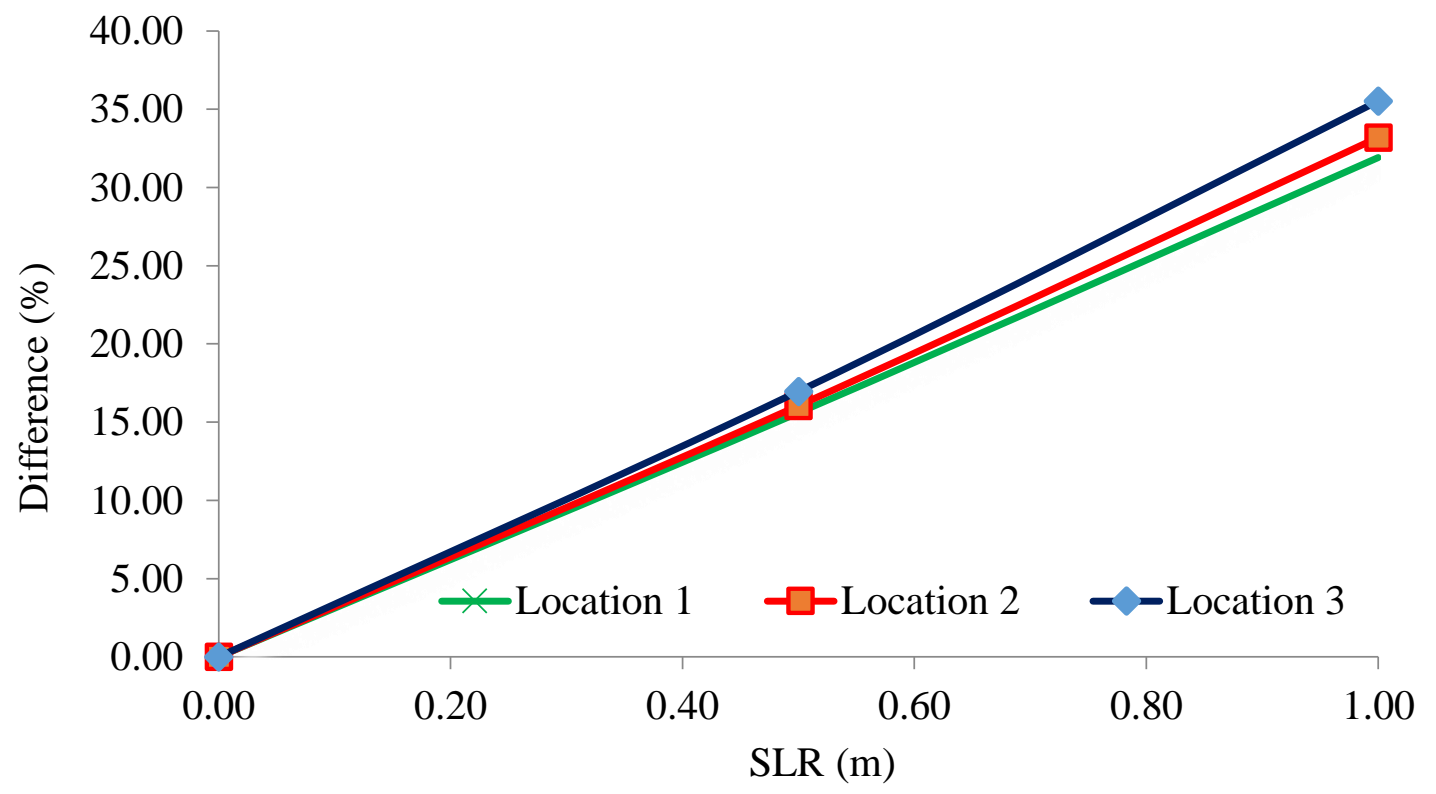

Figure 11. For the largest wave, difference in wave power under the influence of SLR.

\subsection{Effects of SLR on Currents}

In the study area, the wind waves induce the long shore currents. In order to ascertain their effects on the velocities of currents, various SLR scenarios, and wave conditions were simulated in this paper. Figures 12 and 13 present the current speed $(\mathrm{m} / \mathrm{s})$ at study area beaches, caused by different SLR scenarios for the dominant and maximum wave. Specifically, the highest current velocity of 
$0.271 \mathrm{~m} / \mathrm{s}-0.284 \mathrm{~m} / \mathrm{s}-0.295 \mathrm{~m} / \mathrm{s}$ from the shoreline to a depth of $4 \mathrm{~m}$ at the first location beach generated by the dominant wave are higher than the velocity at other beaches in the SLR scenarios (figure 14). This paradox can be caused by the geography in the research region. When there are SLR conditions, the currents are greater than they would be otherwise. For instance, the current velocity near the first location is increased by 4.69 percent: 8.82 percent at the water depth of 0.0 $\mathrm{m}$ to $3.5 \mathrm{~m}$. (figure 14 ).

The impacts of the maximum wave along with SLR on the modeled cross-shore variation in the current speed at study area beaches are illustrated in figure 10. Without SLR scenarios, the higher wave usually causes a larger current speed at the beach. Specifically, the current speed of $0.5 \mathrm{~m} / \mathrm{s}$ near the first location in the maximum wave condition is increased up to $0.52 \mathrm{~m} / \mathrm{s}$ in the second scenario condition and increased to $0.54 \mathrm{~m} / \mathrm{s}$ in the third scenario. The impacts of the maximum wave along with SLR on the modeled cross-shore variation in the current speed at study area beaches are illustrated in figure 10. Without SLR scenarios, the higher wave usually causes a larger current velocity at the beach. Specifically, the current speed of $0.5 \mathrm{~m} / \mathrm{s}$ near the first location in the maximum wave condition is increased up to $0.52 \mathrm{~m} / \mathrm{s}$ in the second scenario condition and increased to $0.54 \mathrm{~m} / \mathrm{s}$ in the third scenario (figure 15$)$. As SLR $(0.5 \mathrm{~m} \& 1.0 \mathrm{~m})$, most of the current velocities influenced by the maximum wave are increased by $3.44 \%-9.68 \%$ at study area beaches, respectively (figure 15).

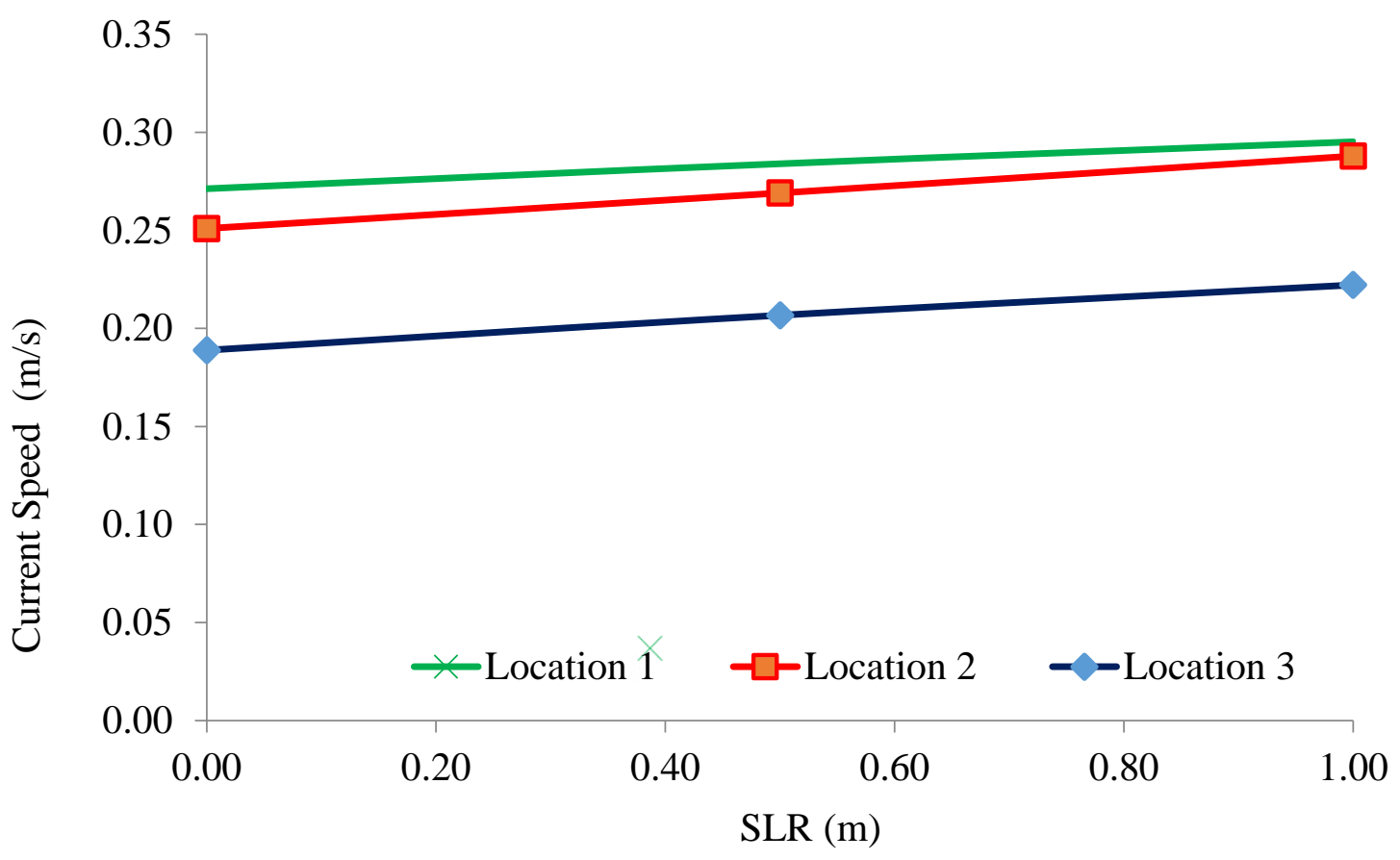

Figure 12. For the dominant wave, current velocity under the influence of SLR. 


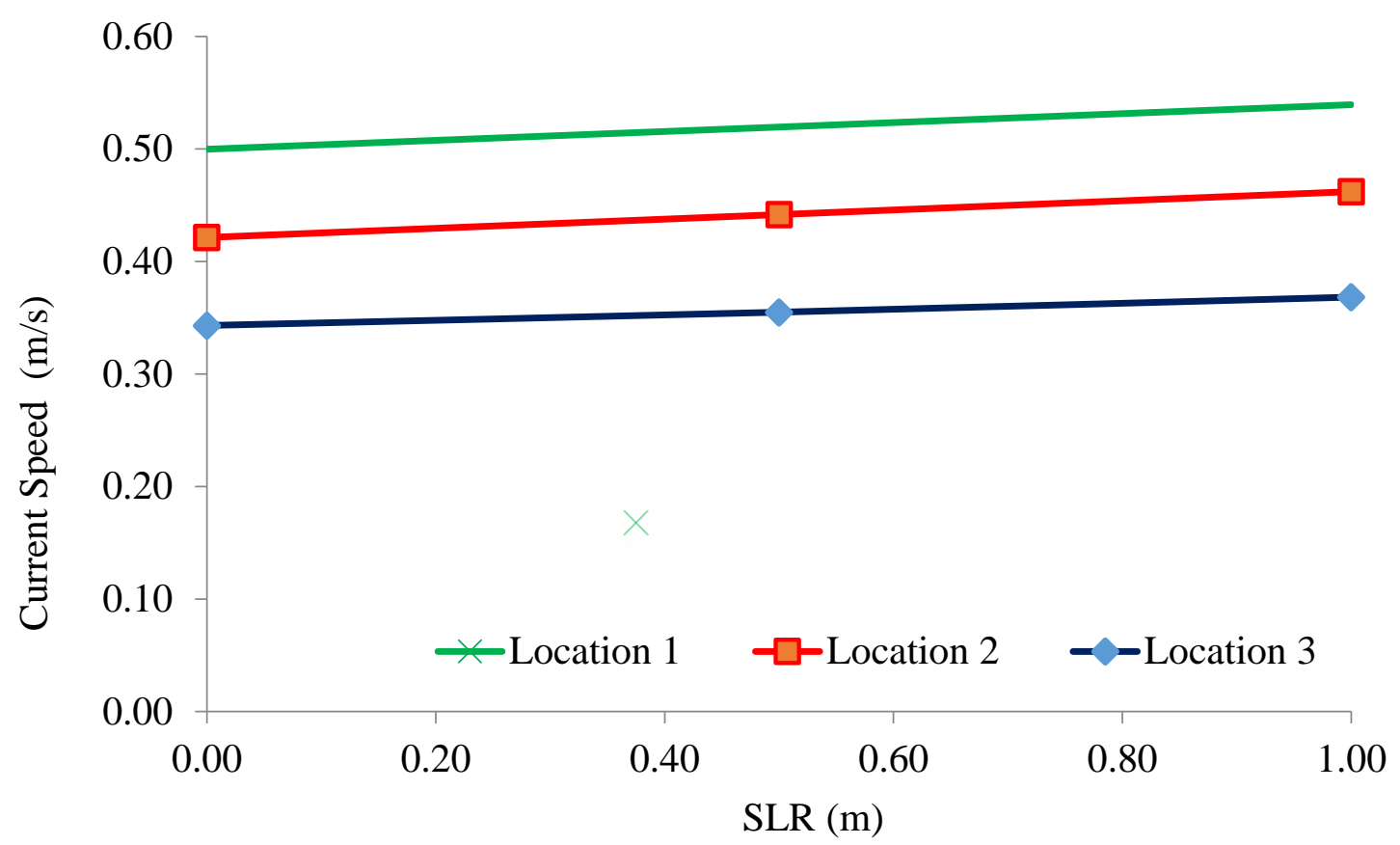

Figure 13. For the maximum wave, current velocity under the influence of SLR.

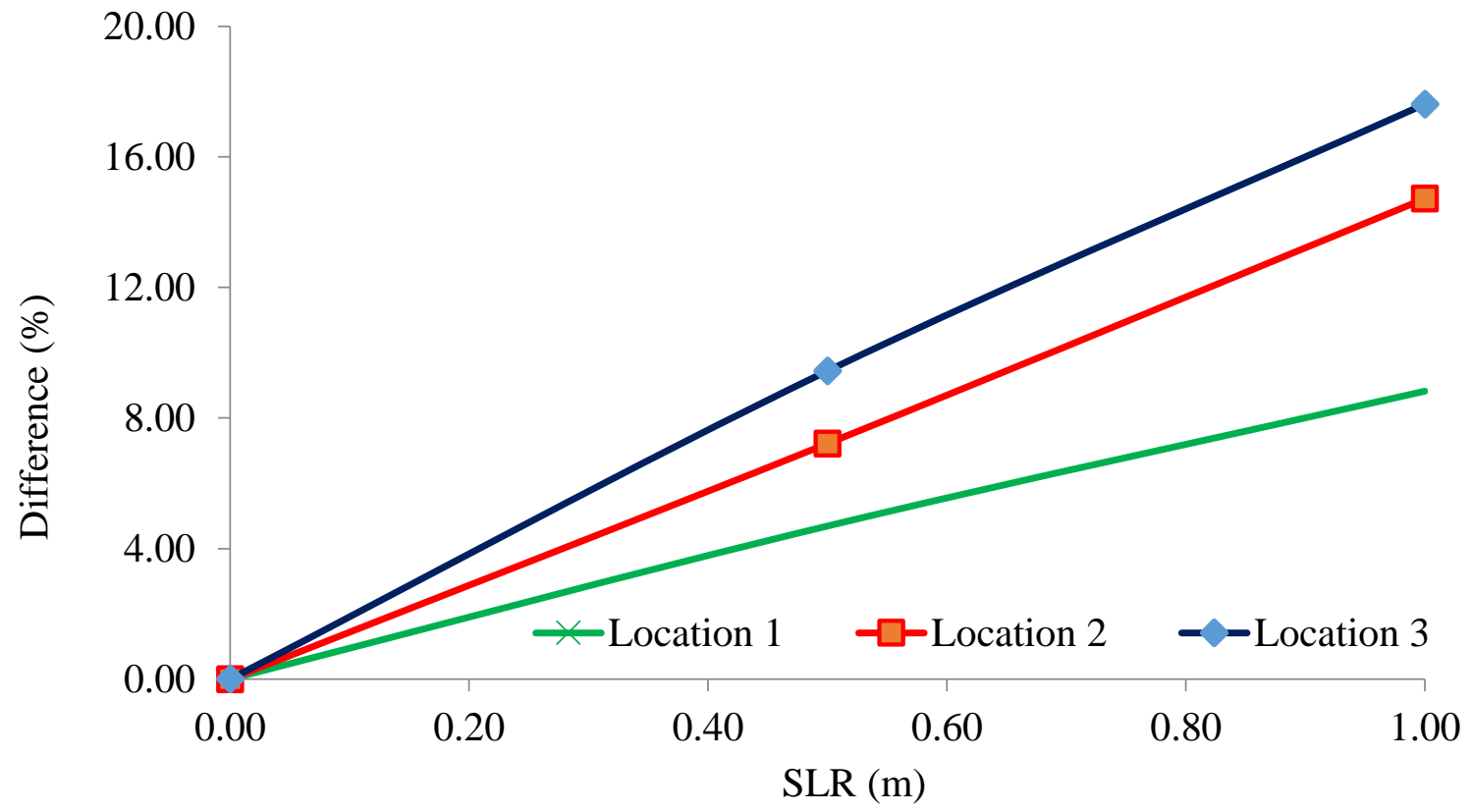

Figure 14. For the dominant wave, difference in current velocity under the influence of SLR. 


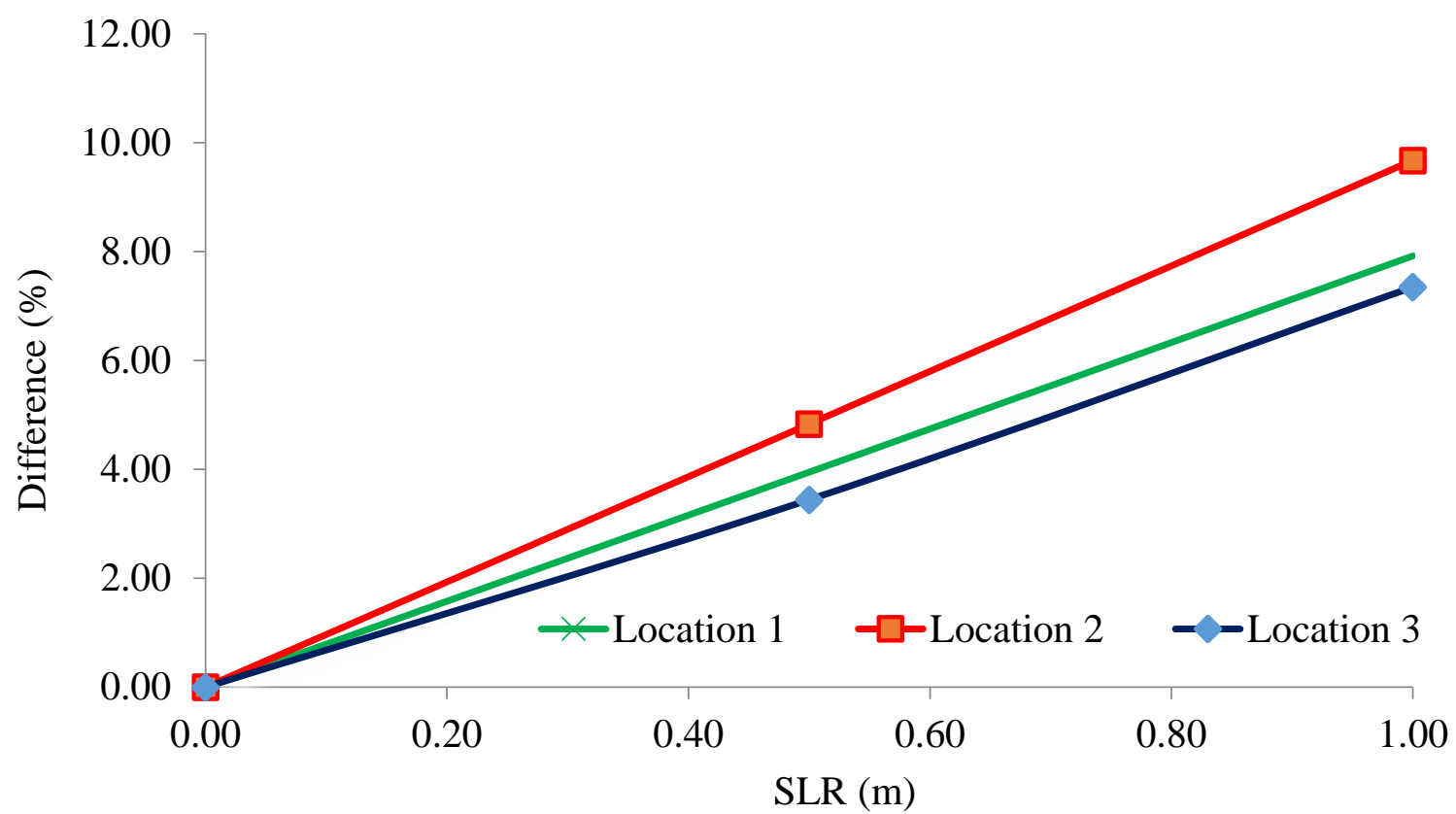

Figure 15. For the maximum wave, difference in current velocity under the influence of SLR.

\section{Conclusions}

The numerical model (MIKE21 (HD, SW)) is used during this study to simulate the variation of the wave characteristic and near-shore current velocity under the effect of SLR. Due to the unavailability of field records for the study area, the numerical model of the study area is validated only by comparison tidal of the numerical model with the available recorded data for a period October 27th to December 14th, 1998. The findings of this study unequivocally demonstrate that SLR causes waves, currents, and wave strength to all dramatically rise. The impact of SLR on the maximum wave condition is about 4-5 times greater than that in the dominant wave condition. Particularly, the average mean wave heights near study area beaches are increased by 1.94\%:2.92\% in the dominant wave condition where they are boosted by $6.55 \%: 12.9 \%$ in the maximum wave condition, compared to those without SLR. The near-shore current speed is increased by 7.12 percent to 14.39 percent in the dominant wave condition, while the maximum wave condition was increased by 4.07 percent to 8.31 percent. The rise in the current velocity mainly leads to a corresponding increase in sediment transport rate. This could be explained by the fact that, as a result of SLR, deeper water areas enable huge waves to approach and break closer to the shoreline, causing more wave energy to damage the shoreline area and transport sand offshore. The results of the numerical model can be accepted where it's suitable to prognosticate the characteristics of extreme waves and currents and descry the dangerous impact of SLR on the littoral area. It is recommended to investigate the sediment transport/pattern and bathymetric changes which are the most common phenomena which should be considered if the data is available for that. 


\section{References}

[1] A. S.A. Mohamed, A. S. I. Koraim, M. I. M. Ibrahim, K. B. Hussein. 2021, “Assessing of the impact of SLR on a vulnerable certain area on Egypt's northern coasts" Proc. Al-Azhar Engineering Fifeenth international Conference.

[2] M. M. E. Abou-Mahmoud. 2021, “Assessing Coastal Susceptibility to Sea-Level Rise in Alexandria, Egypt" TEgyptian Journal of Aquatic Research, Volume 47, Issue 2, June, Pages 133-141

[3] A. Nauels, J. Gütschow, M. Mengel, M. Meinshausen, P. U. Clark, and C. F. Schleussner, "Attributing long-term sea-level rise to Paris Agreement emission pledges," Proc. Natl. Acad. Sci. U. S. A., vol. 116, no. 47, pp. 23487-23492, 2019, doi: 10.1073/pnas. 1907461116.

[4] IPCC, "Sea Level Change,” Fifth Assess. Rep. Intergov. Panel Clim. Chang., 2013.

[5] A. Cazenave and G. Le Cozannet, "SLR and its coastal impacts," Earth's Futur., vol. 2, no. 2, pp. 15-34, 2014, doi: 10.1002/2013ef000188.

[6] T. Frederikse et al., "The causes of sea-level rise since 1900," Nature, vol. 584, no. December 2019, 2020, doi: 10.1038/s41586-020-2591-3.

[7] R. Lindsey, "Climate Change: Global Sea Level," NOAA Climate.gov, 2021. https://www.climate.gov/news-features/understanding-climate/climate-change-global-sealevel.

[8] P. L. Woodworth et al., "Forcing Factors Affecting Sea Level Changes at the Coast," Surv. Geophys., vol. 40, no. 6, pp. 1351-1397, 2019, doi: 10.1007/s10712-019-09531-1.

[9] M. L. Timmermans and J. Marshall, "Understanding Arctic Ocean Circulation: A Review of Ocean Dynamics in a Changing Climate," J. Geophys. Res. Ocean., vol. 125, no. 4, pp. 1-35, 2020, doi: 10.1029/2018JC014378.

[10] D. Stammer, A. Cazenave, R. M. Ponte, and M. E. Tamisiea, "Causes for contemporary regional sea level changes,” Ann. Rev. Mar. Sci., vol. 5, no. September, pp. 21-46, 2013, doi: 10.1146/annurev-marine-121211-172406.

[11] J. Aucan, "Effects of Climate Change on Sea Levels and Inundation Relevant to the Pacific Islands," Pacific Mar. Clim. Chang. Rep. Card Sci. Rev., pp. 43-49, 2018.

[12] DHI, “MIKE 21 Flow Model User Manual,” Danish Hydraul. Inst., 2012.

[13] DHI, "MIKE 21 \& MIKE 3 Flow Model FM Hydrodynamic Module Short Description," pp. 1-64, 2017.

[14] DHI, “MIKE 21 Spectral Wave Module Scientific Documentation MIKE,” Danish Hydraul. Inst., 2012. 